Revue de droit comparé du travail et de la sécurité sociale

\title{
4 | 2017
}

English Electronic Edition

\section{Double Trouble: Consulting for a Fair Retrenchment}

Rochelle Le Roux

\section{(2) OpenEdition}

1 Journals

Electronic version

URL: https://journals.openedition.org/rdctss/2307

DOI: $10.4000 /$ rdctss.2307

ISSN: 2262-9815

Publisher

Centre de droit comparé du travail et de la sécurité sociale

\section{Printed version}

Date of publication: 1 December 2017

Number of pages: 154-161

ISSN: $2117-4350$

\section{Electronic reference}

Rochelle Le Roux, "Double Trouble: Consulting for a Fair Retrenchment", Revue de droit comparé du travail et de la sécurité sociale [Online], 4 | 2017, Online since 01 November 2021, connection on 04 December 2021. URL: http://journals.openedition.org/rdctss/2307 ; DOI: https://doi.org/10.4000/ rdctss. 2307

\section{(c) (†) $९$}

Revue de droit comparé du travail et de la sécurité sociale est mise à disposition selon les termes de la Licence Creative Commons Attribution - Pas d'Utilisation Commerciale - Pas de Modification 4.0 International. 


\section{DOUBLE TROUBLE: \\ CONSULTING FOR A FAIR RETRENCHMENT}

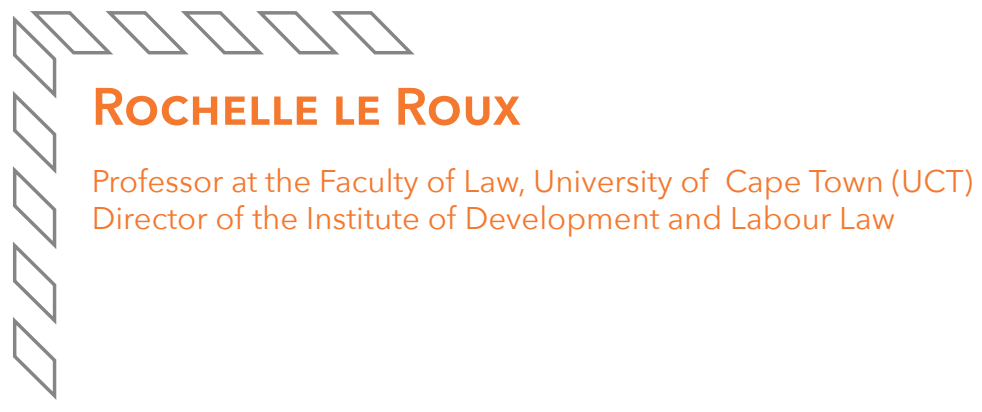

$\mathrm{n}$ South Africa the term 'retrenchment' is colloquially used to describe what the drafters of the Labour Relations Act 66 of 1995 (LRA) chose to call a 'dismissal based on operational requirements'. While the term 'redundancy' is often used in this context, redundancy is regarded as simply one operational requirement justifying dismissal and, unlike in some other jurisdictions, does not mean the same as 'dismissal based on operational requirements' or 'retrenchment'. ${ }^{2}$

Not every dismissal is outlawed by the LRA - only unfair dismissals. ${ }^{3}$ Dismissal law as expressed in the LRA is informed by a view that every dismissal has substantive and procedural aspects, and that it is possible to determine the fairness, or the lack of fairness, of each of these aspects, independent of the other. While this distinction can be made in many cases, in practice, as will be illustrated below, it is not always possible to make this distinction.

The LRA identifies three broad factors that will constitute fair reasons for dismissal: misconduct, incapacity, and the employer's operational requirements. ${ }^{4}$ Demonstrating that one of these reasons informed the dismissal will usually satisfy the requirement of substantive fairness. However, the inquiry is more nuanced than it initially appears. The LRA defines an operational requirement as a requirement based on the economic, technological, structural or similar needs

Section 188(1) of the LRA.

2 R le Roux, Retrenchment Law in South Africa (2016) 2-3.

3 Section 185 of the LRA.

4 Section $186(1)$ of the LRA. 
of an employer. ${ }^{5}$ The substantive fairness of a retrenchment will depend on whether an operational requirement as defined in the LRA in fact motivated the employer's decision to retrench, ${ }^{6}$ but also on whether the dismissal is a fair consequence of the particular operational requirement relied on. This implies that the mere existence of operational requirements within the meaning of the LRA does not by itself validate a subsequent retrenchment; the employer still needs to prove that it was a fair option in the circumstances: ${ }^{7}$ This will primarily depend on whether the employer had alternative employment available and whether the employer applied fair and objective criteria in selecting employees for retrenchment. The reasoning is that if the employer fails to offer alternative employment where such employment is available, or applies selection criteria that are not fair and objective, or applies fair and objective criteria incorrectly, such action results in the dismissal of an employee who should not have been dismissed. This will render the retrenchment substantively unfair. ${ }^{8}$

Key to fair procedural fairness in the case of retrenchment is that retrenchment can be effected only after notice and consultation on a number of topics with affected employees, either through their trade unions or directly with them. ${ }^{9}$ This illustrates the difficulty of distinguishing between substantive and procedural fairness. Not consulting on a statutorily prescribed topic will render the subsequent retrenchment procedurally unfair, but implementing that topic, regardless of whether it has been consulted on, speaks to substantive fairness. This implies that the subsequent retrenchment can still be substantively fair even if no consultation on that topic had taken place. This can be explained with reference to the criteria for selection for retrenchment - a statutorily prescribed topic for consultation. ${ }^{10}$ However, while consultation is required, there is no requirement that consensus be reached. After the required consultation has taken place, the employer may then proceed with the retrenchment using fair and objective criteria, regardless of whether consensus has been reached. Failure to consult on the selection criteria will render the retrenchment procedurally unfair. However, in the absence of an agreement, failure to use

5 Section 213 of the LRA. It is accepted that an employer may retrench in order to make a profit, although this is not discussed in this article. In Fry's Metals (Pty) Ltd $v$ National Union of Metalworkers of SA \& others (2003) 24 ILJ 133 (LAC) the LAC confirmed that the LRA 'recognizes ... an employer's right to dismiss for a reason based on its operational requirements without making any distinction between operational requirements in the context of a business the survival of which is under threat and a business which is making profit and wants to make more profit.' Nonetheless, when employers retrench for profit motives, they can expect a very rigorous examination of both the substantive fairness and procedural fairness of a dismissal.

6 It is fairly obvious that a retrenchment that is not truly based on the employer's operational needs, but is rather an attempt to dismiss an employee for his or her misconduct, will be substantively unfair. This does not imply that the employee cannot be dismissed for misconduct, but simply that it cannot be done under the guise of retrenchment.

7 NEHAWU v The Agricultural Research Council [2000] 9 BLLR 1081 (LC) para 27.

8 Le Roux 31. Section 189(2) of the LRA lists the topics that must be on the consultation agenda. These topics are:

'(a) appropriate measures - (i) to avoid the dismissals; (ii) to minimise the number of dismissals;

(iii) to change the timing of the dismissals; and (iv) to mitigate the adverse effects of the dismissals;

(b) the method for selecting the employees to be dismissed; and

(c) the severance pay for dismissed employees.'

9 Section 189 of the LRA.

10 Le Roux 122. 
criteria that are fair and objective will render the dismissal substantively unfair. This is so because if the 'wrong' criteria are applied, the dismissal of an employee who should not have been dismissed can occur. Put differently, the absence of meaningful consultation on selection criteria does not per se imply that the selection criteria eventually used were not fair and objective and that the retrenchment was substantively unfair. This strange alchemy between substantive fairness and procedural fairness can further be explained with reference to another statutory topic for consultation, namely, appropriate measures to avoid the dismissal. The employer consulting on the means of providing the employee with alternative employment will in all likelihood rescue the procedural fairness of the dismissal, even if the alternative employment is not provided. However, not providing alternative employment that is available will render the dismissal substantively unfair.

The above general principles apply to all retrenchments, regardless of the number of employees employed by the employer and regardless of the number of employees that the employer wishes to dismiss. However, in 2002, the legislature introduced a number of procedural variations in the case of large-scale retrenchment. ${ }^{11}$ These provisions apply when an employer employs more than 50 employees and contemplates retrenching at least 10 employees. Generally, the onus is entirely on the employer to decide whether it has consulted in a meaningful way and the employer can halt the consultations if it is satisfied that it has consulted even if no consensus was reached. However, in the case of a large-scale retrenchment, the employer is required to allow certain minimum periods for consultation before it may proceed with the retrenchment. Additionally, in the case of a large-scale retrenchment, the parties are entitled to ask a third party to facilitate the consultation.

The rest of this article will focus on certain aspects of the substantive fairness of retrenchment and in doing so will examine two recent judgments of the Labour Appeal Court (LAC) and the Labour Court (LC) respectively. This first matter, Blinkwater Mills (Pty) Ltd $v$ Kgalegi'2 (Blinkwater Mills), illustrates the need for the employer to demonstrate not only the existence of an operational requirement, but that the operational requirement relied upon truly necessitated a reduction of employees. Blinkwater Mills further illustrates the employer's responsibility to offer alternative employment to the employee who is at risk of being retrenched where such an alternative is available. The second matter, SACCAWU and Others $v$ Woolworths (Pty) Ltd ${ }^{13}$ (Woolworths), illustrates an employer's failed attempt to justify pay equity as the basis for retrenchment. 


\section{I - OPERATIONAL REQUIREMENTS AND ALTERNATIVE EMPLOYMENT}

Hitherto, the courts have taken a very dim view of employers addressing employees' misconduct or poor performance under the guise of retrenchment. This is not simply because the courts take a rigid authoritarian approach. The distinction between dismissal for misconduct, poor performance or operational requirements relates to jurisdiction. ${ }^{14}$ The labour courts have jurisdiction only to adjudicate retrenchments and, since the labour court is a creature of statute, it cannot assume jurisdiction in respect of a dismissal, unless such jurisdiction has specifically been granted by statute. However, even in cases where retrenchment is not used as a pretext, the courts have been reluctant to accept that an apparent operational requirement such as restructuring would necessarily imply redundancy, unless this is borne out by subsequent events. This is illustrated by the LAC's judgment in Blinkwater Mills. In this matter the employer operated a business that consisted of a head office and a number of branch offices. The employer decided to centralise its human resources services and this resulted in the employee losing his employment at the branch where he was working. The LC and the LAC did not appear to question the need to centralise human resources, but both had serious reservations about whether it was in fact necessary for the employee to lose his job as a result of this. Put differently, did the employee's position truly become redundant as a result of the centralisation initiative? The employer claimed that this was the case, but the evidence showed that the work of the retrenched employee was not simply reallocated to another incumbent employee; in fact, another employee was hired in order to manage the restructured functions at the head office. This suggested to the LAC that there was no true redundancy as the retrenched employee's 'job functions were not of such a nature that they could be tagged on to another employee's tasks without causing further restructuring and a new appointment.'15

The court also questioned whether the employer consulted in a meaningful way in order to avoid dismissal or to seek alternative employment for the employee. The evidence suggested that the affected employee was tested, but found to be inadequately skilled for an accounting-related post. However, the evidence further suggested that during consultation the employer mentioned a suitable position, but at a reduced salary, that was possibly becoming vacant at another branch. ${ }^{16}$ The vacancy depended on the outcome of a medical report about the incumbent, who had health problems. However, the employer proceeded with the retrenchment without revisiting this potential vacancy which in fact became available subsequently. In this regard the court emphasised the importance of an employer seeking all possible ways of avoiding a retrenchment; this included making alternative positions available where they became vacant. Concluding the consultations and proceeding with retrenchment before getting clarity about the potential vacancy suggested to the court that the employer failed to consult with the correct approach: 'To be meaningful, the consultation must be genuine and may not be a sham with the purpose of seeking alternatives to dismissal [aiming] to avoid dismissal if reasonably possible. ${ }^{17}$ The failure to consult adequately rendered the retrenchment unfair. This aspect of the judgment illustrates the fine line between substantive fairness and procedural fairness: not

\footnotetext{
14 Le Roux 17.

15 Para 27

16 Para 9.

17 Para 30
} 
consulting on an alternative position renders the dismissal procedurally unfair; not offering the alternative position relates to substantive fairness, as offering the position could have completely avoided the need to retrench.

This inevitably raises the question of the legal position when the employer offers alternative positions, but at a reduced remuneration, although this was not addressed in the judgment. This should be understood in the context of severance pay: In the absence of agreement on severance pay, an employer must pay an employee who is retrenched severance pay equal to at least one week's remuneration for each completed year of continuous service with that employer. ${ }^{18}$ However, an employee who unreasonably refuses to accept the employer's offer of alternative employment with that employer or any other employer forfeits severance pay. ${ }^{19}$ This raises the question of when an employee is entitled to reasonably refuse alternative employment and, as a consequence, still be entitled to severance pay. Refusing alternative employment in the following circumstances has been held to be reasonable: a drastic reduction of status, new responsibilities beyond the capabilities of the employee, or a relocation affecting the employee's personal circumstances. In Astrapak Manufacturing Holdings (Pty) Ltd t/a East Rand Plastics v Chemical Energy Paper Printing Wood \& Allied Workers Union ${ }^{20}$ the LAC established the basic guideline that if the employee is offered alternative employment with the same or increased remuneration, it would generally be unreasonable to refuse the alternative employment. While the LAC in Astrapak avoided making a firm pronouncement, the court suggested that when an employee is faced with alternative employment that involves a wage decrease, it cannot be said that the employee is acting unreasonably if he or she refuses such alternative employment.

Reverting to the facts in the case of Blinkwater Mills, it can asked what the implications would have been if the employer had indeed offered the vacant position to the employee, but at a reduced salary. If the offer had been made and accepted, that would have been the end of the matter, and the employee would not have been entitled to severance pay. Not making the offer would have rendered the dismissal substantively unfair since there was a means of avoiding the retrenchment. ${ }^{21}$ In other words, offering the position implies that the risk of substantive unfairness is substantially reduced in the event of the offer not being accepted. Furthermore, if this offer had been made during a fair consultation process, the risk of procedural unfairness would also have been avoided. However, this does not imply that the employer is relieved of the duty to pay severance pay because the employee refused to accept the offer of alternative employment. This would be the case only if it can be said that the employee unreasonably refused the offer. Based on the approach in Astrapak it would not be unreasonable to refuse alternative employment at a reduced salary, and for that reason the employee would be entitled to severance pay.

18 Severance pay is regulated by section 41 of the Basic Conditions of Employment Act 75 of 1997 (BCEA).

19 Section 41(4) of the BCEA.

20 (2014) 35 ILJ 140 (LAC).

21 Masilela v Leonard Dingler (Pty) Ltd (2004) 25 ILJ 544 (LC) paras 34-35. 


\section{II - OPERATIONAL REQUIREMENTS AND PAY EQUITY}

As stated earlier, generally, the misconduct and incapacity of the employee should not be the basis for a dismissal based on the employer's operational requirements. Nonetheless, it is sometimes difficult to distinguish misconduct and incapacity from genuine operational requirement dismissals. For instance, theft is clearly a disciplinary matter, but where theft results in serious stock losses, and eventually affects financial viability, it will be difficult to argue that retrenchment is not a legitimate option. However, employers cannot retrench simply because it is in a particular case easier than following a misconduct or incapacity procedure. Assuming that evidence is available, the question is whether the operational need of the employer, or misconduct or incapacity, is the dominant reason for the dismissal. ${ }^{22}$ Difficult as this distinction may be, an even more complicated distinction is the one to be made between a genuine operational requirement and unfair discrimination. Unsurprisingly, South African law places a high premium on employment equity and has passed specific legislation in the form of the Employment Equity Act 55 of 1998 (EEA) to facilitate, amongst other things, the promotion of equal opportunity and fair treatment in the workplace by eliminating unfair discrimination. Although this approach was previously not expressed in such terms, it has always been recognised that this requires equal pay for work of equal value and that it is not permitted to distinguish pay on the basis of grounds such as race, gender, sex, marital status, ethnic or social origin, or any other arbitrary ground. However, in 2013 the EEA was amended in order to regulate pay equity more explicitly. The newly inserted section 6(4) of the EEA provides as follows:

A difference in terms and conditions of employment between employees of the same employer performing the same or substantially the same work or work of equal value that is directly or indirectly based on any one or more of the grounds listed in subsection (1) [ie the grounds listed above] is unfair discrimination.

To what extent can the need to meet the legislative demand of pay equity become an operational requirement? The relationship between operational requirements, equal pay and discrimination was explored in the LC's judgment in Woolworths; ${ }^{23}$ more specifically, the court considered whether the need to ensure pay equity is an operational requirement. Woolworths, a major food and clothing retailer in South Africa, at the time employed 16400 flexi-timers and 590 full-timers in its 200 corporate stores. Generally, the full-timers earned substantially more than the flexi-timers. Citing three operational requirements drivers, namely, flexibility, cost efficiency, and equality, Woolworths embarked on a restructuring exercise aimed at converting the full-timers to flexi-timers. The need for flexibility was not seriously disputed, but the affected employees questioned the need for the reduction of their salaries to the levels that applied to the flexi-timers. Woolworths' cost-saving rationale was rejected based on the lack of evidence about the costs associated with the employment of full-timers and the potential savings. For the purpose of this discussion, Woolworths' more interesting reasoning related to the (then) impending pay equity legislation requiring employers to address income differentials and pay discrimination, and Woolworths' concomitant need to manage the risk of its exposure to equal pay claims from the flexitimers. 
The LC was not convinced by this argument. The court held that the impending legislation, but even the general anti-discrimination laws that pre-dated the new laws, acknowledged that any identified differentiation creates a possible justification. ${ }^{24}$ More specifically, regulations ${ }^{25}$ adopted in order to support the implementation of the new legislation indicate, inter alia, that seniority and length of service can justify a pay difference for individuals performing work of equal value. Since, on the facts of this matter, the fulltimers generally had longer service than the flexi-timers, a justification existed for continuing to pay them on the higher level, despite the rest of their conditions of service being adjusted to those of the flexi-timers. ${ }^{26}$ Furthermore, the regulations further anticipated the situation in this matter and specifically provide that where an employee is demoted as a result of organisational restructuring, it is valid to fix that employee's salary at the higher level until the remuneration of employees in the same job category reaches that level. ${ }^{27}$ The amended legislation further requires an employer to develop a plan to deal progressively with any unfair pay differentiation where it does exist; ${ }_{i}^{28}$ the implied sentiment is therefore that the employer has some leeway to correct pay inequities through incremental means once it has identified the inequity. ${ }^{29}$ However, even if it could be said that a justification existed for converting all the full-timers to flexi-timers at reduced pay, an onus remains on the employer throughout to avoid a dismissal that can be avoided. With this in mind, the LC concluded that this could have been achieved through the less drastic measure of natural attrition. ${ }^{30}$ The dismissals of the retrenched employees were thus held to be substantively and procedurally unfair, and Woolworths was ordered to reinstate them retrospectively from the date of their dismissal without loss of pay. ${ }^{31}$

24 Para 34

25 See EEA Regulations, as repealed by the Minister of Labour in a notice published under GN 378733 of 1 August 2014.

26 Para 40

27 Para 42

28 See s 27 of the EEA. Further see Code of Good Practice on Equal Pay/Remuneration for Work of Equal Value, gazetted under GN 38837, issued on 1 June 2015 by the Minister of Labour in terms of section 54(1) of the Employment Equity Act, 1998 (Act No 55 of 1998 as amended).

29 Para 45

30 Para 53

31 Since this note was first published, this matter was taken on appeal to the Labour Appeal Court. See Woolworths (Pty) Ltd v SACCAWU and Others (JA56/2016) [2017] ZALAC 54; [2017] 12 BLLR 1217 (LAC) (19 September 2017). The appeal court did not understand the employer's case to be that pay equity was the operational requirement that necessitated retrenchment. Instead, the court accepted that the need to work flexi-time resulting in cost and operational efficiencies was a valid reason for restructuring and that the dismissal of full-time employees not prepared to convert to flexi-time was the reason for retrenchment. The court thus accepted that equity considerations were not the purpose of the exercise. Nonetheless, it held that the dismissals were unfair because there was not a proper consideration of alternatives and ordered the payment of compensation instead of reinstatement. While the judgment of the Labour Court has become obsolete because it took a different view of the equity considerations, its judgment would be useful when in future the need to meet the requirements of new legislation is held out to be an operational requirement. 


\section{CONCLUSION}

The analysis above illustrates the complicated relationship between substantive fairness and procedural fairness. Although they can generally be regarded as two independent pillars, this assumption does not always hold true, especially in the case of retrenchment. The analysis further illustrates the necessity of showing that the retrenchment is based on, and a necessary consequence of, an operational need. The inquiry into the fairness of retrenchment starts by establishing whether it was based on an operational need of the employer. There is no operational need (based on redundancy) if the employer needs to employ another employee to replace the retrenched employee (Blinkwater Mills) and it will be difficult to argue that pay equity, in isolation, can justify retrenchment (Woolworths). However, even if it can be said that there is a valid operational need, the mere existence of an operational need does not justify the subsequent retrenchment if the dismissal could have been avoided by offering available alternative employment (Blinkwater Mills). 